\title{
Impact of Environmental Issues on Consumer Senses Leading to Ecofriendly Buying Decisions
}

\author{
Hannah Fredrick, J. Salomi Backia Jothi
}

\begin{abstract}
Inducing Sustainable consumption in individuals is one of the important challenges in the path to Sustainability. Buying decision can be influenced by Consumer Perception. Sensory Marketing practices are effective tools for influencing Consumer Perception. This paper introduces sensory marketing as a new replica in the field of Sustainable Consumption. Senses stimulate cognitive thinking which is the need of the hour for global environmental change. Sensory marketing may be a new tool in the field of solving Environmental issues, as it influence buying decisions of consumer and also encourage consumer to pay more through perception. This study tries to analyse the impact of environmental Issues on consumer senses which influences to Eco friendly buying decisions..
\end{abstract}

Keywords : Environmental Issues, Sensory Marketing, Eco Friendly Buying Decisions.

\section{INTRODUCTION}

$E_{\text {nvironmental issues have gained more importance in }}$ the society now-a-days. Environmental consciousness of individual has also grown. Purchase of environmentally friendly consumables product has to be encouraged to have more environmental benefits. Triggering the subconscious of the consumer may influence a change in consumer perception and buying behavior. Sensory Marketing engages the basic senses of consumer to influence their perception and behavior. So the main aim of this paper is to analyse the impact of sensory marketing in the field of sustainable consumption

\section{A. Need for the study}

Sensory marketing may be a new tool in the field of solving Environmental issues, as it influence buying decisions of consumer and also encourage consumer to pay more through perception. Seeing ,Hearing, tasting ,smelling and touching plays an important role in satisfying day to day needs.

Revised Manuscript Received on December 05, 2019.

* Correspondence Author

Dr. Hannah Fredrick*, Associate Professor \& Research Supervisor, Department of Commerce, Madras Christian College (Autonomous), Affiliated to University of Madras, East Tambaram ,Chennai, India. E-Mail: hfgfef@gmail.com

J. Salomi Backia Jothi, Research Scholar, Department of Commerce, Madras Christian College (Autonomous), Affiliated to University of Madras, East Tambaram, Chennai, India.

E-Mail: salomi.jeswin@gmail.com

\section{B. Conceptual Frame work of the Study}

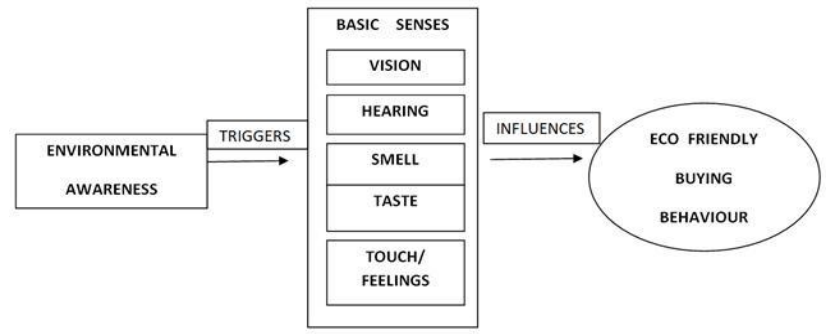

\section{Research Gap}

Sensory Marketing practices are effective tools for influencing Consumer Perception. This paper introduces sensory marketing as a new prototype in the field of Sustainable Consumption.

\section{REVIEW OF LITERATURE}

Individual Concern for the environment is the basic necessity.Environmental concern have direct impact on green buying behavior Kim and Choi(2005)..,Many studies reveals that influencing consumer perception have an impact on purchasing decisions of the consumer. Sensory marketing means studying the basic senses and consumer behavior. Environmental stimuli lead to an emotional reaction of the consumers which brings out consumer behavioural response.( Mehrabian and Russell 1974). Vision- Edwards and Shackley, 1992 says due to effective exterior store window the sales have been increased.In Marketing research vision is an important sense (Krishna, 2012; Schroeder,2006). Sound has impact on many consumer behavior. According to Yoon and Park, 2011, Sensory marketing is related with a favourable emotional response in the consumer's shopping behavior. Consumer's senses, experience and emotions have been emerging as important paradigm(Achrol and Kotler, 2010). The environmental stimuli in the store influences consumer behavior ( Farias et al.2014)

\section{RESEARCH METHODOLOGY}

\section{A. Sampling design}

The sample for this research was taken from the youth in Chennai, Tamil Nadu. Every segment of the population is responsible for maintaining the Environmental Integrity. Youth are having special responsibility as they will be the ones to inherit it. 
A questionnaire was framed and tested for its suitability and applicability to this research study. After testing its reliability, the questionnaire was administered to 280 youths. After discarding questionnaires that was incomplete, 220 questionnaires were selected for the study.

\section{B. Objectives}

1. To identify impact of environmental issues influencing the 5 basic senses of the youth

2. To find the relationship between environmental issues influencing the senses and purchase of eco friendly products.

\section{Hypothesis}

1. Environmental issues influencing the senses leads to purchase of eco friendly products

\section{DATA ANALYSIS}

\section{A. Application of Structured Equation Model (SEM) on the influence of environmental issues on 5 basic senses of the youth}

The environmental issues influence the 5 basic senses (Sight, Hearing, Smell, Touch and Taste) of the youth. Sight and hearing senses are combined and taken as Audio visual senses as both are related. Touch senses is related to feelings and Taste senses is related to food. 10 variables of environmental issues influencing the 5 basic senses of the youth was taken for the study.

a) Factor Analysis on the variables of environmental issues influencing the 5 basic senses of the youth

Factor analysis was adopted on the 10 variables of environmental issues influencing each of the 5 basic senses of the youth. Factor analysis was applied using SPSS 21 on

4.1.1(a) Factor Analysis on the variables of environmental issues influencing the Audio Video senses of the youth

The researcher identified the 10 variables taken from previous research studies that constitute the variables of environmental issues that influence the Audio Video senses of the youth as land slide, earth quake, global warming, water scarcity, deforestation, wasting fuels, plastic usage, co2 emission, industrial waste and ocean pollution. Principal Component method and Varimax rotation with showed Kaiser-Meyer-Olkin Statistic to be $0.922(>0.7)$ and Barlett's test of Spericity $(\square 2=1400.549, \mathrm{p}=0.000)$ significant with a cumulative $\%$ as 69.879 , thereby confirmed the feasibility of factor analysis. As 9 variables fell within the 1 st factor and 1 variable landslide fell in the 2nd factor, the 9 variables constituting the 1st factor was taken for the study as they were considered important variables of environmental issues that influence the Audio Video senses of the youth.

4.1.1(b) Factor Analysis on the variables of senses of the youth these variables. environmental issues influencing the Touch/ Feelings

The researcher identified the 10 variables taken from previous research studies that constitute the variables of environmental issues that influence Touch/ Feelings senses of the youth as fear of natural calamities, fear of global warming, fear of future of environmental degradation, fear of survival, fear of health issues, fear of industrial explosions, fear of safety to life, fear of accidents, fear of non availability of resources and fear of future generation survival. Principal Component method and Varimax rotation with factor showed Kaiser-Meyer-Olkin Statistic to be 0.921 (>0.7) and Barlett's test of Spericity ( $\square 2=1334.858, \mathrm{p}=0.000$ ) significant with a cumulative $\%$ as 60.091, thereby confirmed the feasibility of factor analysis. As all the 10 variables fell within one factor, all the variables were considered as important variables of environmental issues influencing the Touch/ Feelings senses of the youth.

4.1.1(c) Factor Analysis on the variables of environmental issues that impact the Smell senses of the youth

The researcher identified the 10 variables taken from previous research studies that constitute the variables of environmental issues that influence the Smell senses of the youth as water pollution smell, air pollution smell, plastic burning smell, land pollution smell, garbage smell, drainage leakage smell, Industrial smoke smell, fast food odor smell, chemical smell, and junk food odor smell. Principal Component method and Varimax (orthogonal) showed Kaiser-Meyer-Olkin Statistic to be 0.857 (>0.7) and Barlett's test of Spericity $(\square 2=1434.310, \mathrm{p}=0.000)$ significant with a cumulative $\%$ as 69.347 , thereby confirmed the feasibility of factor analysis. As 8 variables fall within the 1 st factor and 2 variable fall in the 2 nd factor, the fast food odor smell and junk food odor smell, 8 variables constituting the 1 st factor was take for the study as they were considered important variables of environmental issues influencing the Smell senses of the youth.

4.1.1(d) Factor Analysis on the variables of environmental issues influencing the Taste/ Food senses of the youth

The researcher identified the 10 variables taken from previous research studies that constitute the variables of environmental issues that influence the Taste/ Food senses as avoiding nutritious food, unsaturated fatty food, preservatives in food, adulterated food, chemicals in food, unhygienic food, junk food, avoiding traditional food, canned food and fast food. Principal Component method and Varimax (orthogonal) showed Kaiser-Meyer-Olkin Statistic to be $0.861 \quad(>0.7)$ and Barlett's test of Spericity $2=1500.904, \mathrm{p}=0.000$ ) significant with a cumulative $\%$ as 71.364 , thereby confirmed the feasibility of factor analysis. As 8 variables fall within the 1st factor and 2 variables junk food and avoiding traditional food fall in the 2nd factor, 8 
variables constituting the 1st factor was take for the study as they were considered important variables of environmental issues influencing the Taste/ Food senses of the youth.

\section{B. Confirmatory Factor Analysis}

After the completion of Exploratory Factor Analysis, the variables in each factor for each senses obtained through Factor Analysis was confirmed by Confirmatory Factor
Analysis (Amos 21.0). Using a maximum likelihood estimation method, the results of CFA signifies if the Senses model fits the data well or not. As taste/ food senses did not fit into the model, taste/ food senses was removed assuming that environmental issues influence on taste/ food senses is insignificant.

Table - I: Reliability and Validity for relation between environmental issues impacting the senses

\begin{tabular}{|c|c|c|c|c|c|c|}
\hline & Reliability & \multicolumn{5}{|c|}{ Validity } \\
\hline & \multirow{2}{*}{ Alpha $>0.7$} & \multirow{2}{*}{ AVE $>0.5$} & \multirow{2}{*}{$\begin{array}{c}\text { Composite } \\
\text { Reliability }>0.7\end{array}$} & \multicolumn{3}{|c|}{ Discriminant Validity } \\
\hline & & & & Audio Visual & Touch & Smell \\
\hline Audio Visual & .930 & .612 & .934 & .782 & & \\
\hline Touch & .926 & .552 & .931 & $.280^{* *}$ & .743 & \\
\hline Smell & .911 & .560 & .923 & $.312 * *$ & $.287 * *$ & .748 \\
\hline
\end{tabular}

Alpha >0.70 Nunnally\&Berstein 1994), AVE >0.50(Ahmad et.al. 2016),CR >0.70(Fornell and Bookstein, 1982)** Correlation is significant at 0.01 level.

Source: Analysis of survey data

The data used in the model are found to be reliable and valid. The Fitness of Data was tested using the Model fit data in Amos and is shown in Table -II.

Table - II: Fit Statistics for the Measurement Model for relation between environmental issues impacting the audio visual senses, touch/ feeling senses and smell senses

\begin{tabular}{|c|c|c|c|}
\hline Name of the Index & Index Value & Acceptance level & Outcome \\
\hline RMSEA & .049 & $\leqslant 0.08$ ( MacCallum et al, 1996) & Good fit \\
\hline CFI & .962 & $\geqslant 0.95$ (Hulland et.al, 1991) & Good fit \\
\hline SRMR & .0515 & $\leqslant 0.08$ Hu \& Bentler & Good fit \\
\hline$\chi^{2 / \mathrm{df}}$ & 1.530 & $<5$ (Marsh et.al, 1985) & Good fit \\
\hline
\end{tabular}

Source: Analysis of survey data

The values of $\chi 2 / \mathrm{df}, \mathrm{CFI}, \mathrm{SRMR}$ and RMSEA indicated a perfect fit.

4.1.3 Structural Equation Model showing the environmental issues influencing the senses

The following Figure - I shows the Structural Equation Model showing the environmental issues influencing the senses

Figure - I

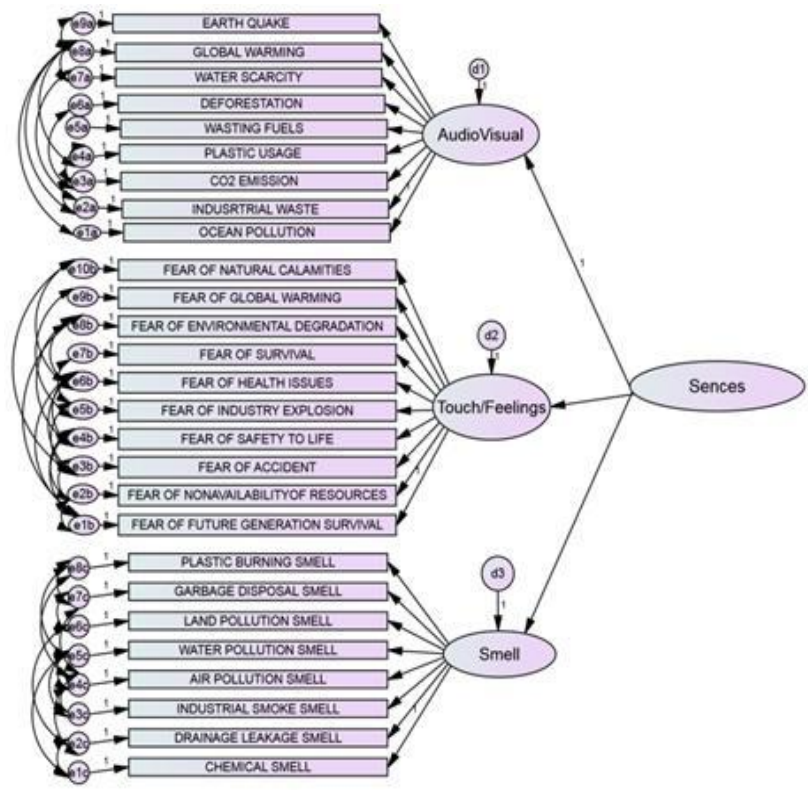

4.2 Application of Structured Equation Model (SEM) for relationship between environmental issues influencing the senses and purchase of eco friendly products. 
4.2.1 Factor Analysis on the purchase of eco friendly products

10 eco friendly products was identified from previous research and factor analysis was applied. The 10 eco friendly products are organic foods, five star gadgets, vehicles with less co2, recycled goods, reusable goods, less chemical products, non plastic goods, renewable energy products, energy conserving products and water saving products. Principal Component method and Varimax (orthogonal) rotatio showed Kaiser-Meyer-Olkin Statistic to be 0.911 $(>0.7) \quad$ and Barlett's test of Spericity
$2=1669.325, \mathrm{p}=0.000)$ significant with a cumulative $\%$ as 65.264 , thereby confirmed the feasibility of factor analysis. As all the 10 variables fell into the same construct, all were considered important variables of purchase of Eco friendly products influenced by senses.

\subsubsection{Confirmatory Factor Analysis}

After the completion of exploratory Factor Analysis, the variables of purchase of Eco friendly products was confirmed by confirmatory Factor Analysis using Amos 21.0..

Table - III: Reliability and Validity for purchase of Eco friendly products

\begin{tabular}{|c|c|c|c|}
\hline & Reliability & \multicolumn{2}{|c|}{ Validity } \\
\hline & Alpha $>0.7$ & AVE $>0.5$ & Composite Reliability $>0.7$ \\
\hline Eco friendly products & .940 & .605 & .944 \\
\hline
\end{tabular}

Alpha >0.70( Nunnally\&Berstein 1994), AVE >0.50(Ahmad et.al. 2016),CR >0.70(Fornell and Bookstein, 1982)**

Source: Analysis of survey data

The data used in the model are found to be reliable and valid.

Table - IV: Fit Statistics

\begin{tabular}{|c|c|c|c|}
\hline Name of the Index & Index Value & Acceptance level & Outcome \\
\hline RMSEA & .048 & $\leqslant 0.08$ ( MacCallum et al, 1996) & Good fit \\
\hline CFI & .999 & $\geqslant 0.95$ (Hulland et.al, 1991) & Good fit \\
\hline SRMR & .0165 & $\leqslant 0.08$ Hu \& Bentler & Good fit \\
\hline$\chi^{2 / \mathrm{df}}$ & 1.142 & $<5$ (Marsh et.al, 1985) & Good fit \\
\hline
\end{tabular}

Source: Analysis of survey data

The values of $\chi 2 / d f, C F I$, SRMR and RMSEA indicated a perfect fit.

4.2.3 Path Model showing the relationship between environmental issues influencing the senses and purchase of Eco friendly products.

\subsubsection{Evaluation of Path diagram}

Table - V: Fit Statistics for the relationship between environmental issues influencing the senses and purchase of eco friendly products.

\begin{tabular}{|c|c|c|c|}
\hline Name of the Index & Index Value & Acceptance level & Outcome \\
\hline RMSEA & .051 & $\leqslant 0.08$ (MacCallum et al,1996) & Good fit \\
\hline CFI & .944 & $\geqslant 0.95$ (Hulland et.al, 1991) & Good fit \\
\hline SRMR & .0508 & $\leqslant 0.08$ Hu \& Bentler & Good fit \\
\hline$\chi^{2 / \mathrm{df}}$ & 1.574 & $<5$ (Marsh et.al, 1985) & Good fit \\
\hline
\end{tabular}

Source: Analysis of survey data

The values of $\chi 2 / d f$, CFI, SRMR and RMSEA indicated a perfect fit.

\subsubsection{Path Model}

SPSS Amos Graphics has specified the path-diagram in Figure 4.3.1 which shows the relationship between the independent variable (environmental issues influencing the senses) and dependent variable (purchase of Eco friendly products).

Figure - II: Relationship between environmental issues influencing the senses and purchase of eco friendly products.
The relationship between environmental issues influencing the senses and purchase of Eco friendly products is established by the Path diagram. 


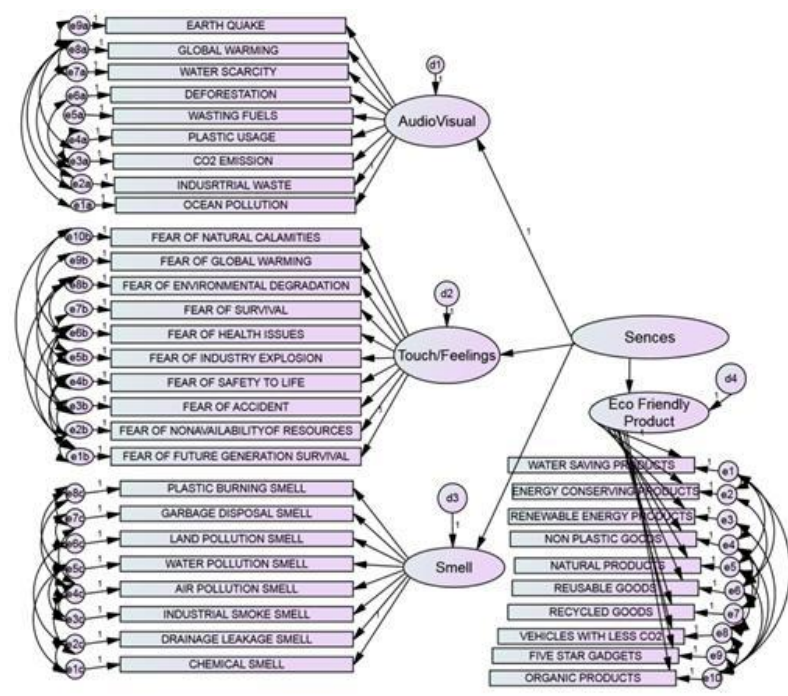

As the model indicates an acceptable fit shown in Table 4.3.2 an examination of the regression weights estimate can be done for the structural model to establish the relationship between the environmental issues influencing the senses and the purchase of eco friendly products.

After evaluating the model fit, the research Hypothesis Ha3"environmental issues influencing the senses leads to purchase of eco friendly products" was tested using the results of the Path analysis.

\subsubsection{Hypothesis Testing based on Standardized Regression estimate}

Table - VI: Regression coefficients of environmental issues influencing the senses and purchase of eco friendly products.

\begin{tabular}{|c|c|c|c|c|c|c|c|}
\hline & & $\begin{array}{c}\text { Standardized } \\
\text { Estimate }\end{array}$ & S.E. & C.R. & P & Results \\
\hline $\begin{array}{l}\text { Purchase of eco } \\
\text { friendly product }\end{array}$ & $<--$ & $\begin{array}{c}\text { Environmental issues } \\
\text { influencing the Senses }\end{array}$ & .518 & .186 & 3.911 & $* * *$ & Ha is supported \\
\hline
\end{tabular}

Source: Analysis of computed data

As the p-value is less than 0.05, the Hypothesis $\mathrm{Ha}$ is accepted.

\section{CONCLUSION}

Out of the 5 basic senses, environmental issues are found to smell senses. Taste/ food senses though influenced by environmental issues, compared to audio visual senses, touch/ feeling senses and smell senses its contribution is seen insignificant. Hence, the youth must be made more conscious found that audio visual senses, touch/ feeling senses and smell senses when triggered by environmental issues, lead the youth to purchase eco friendly products. This proves that the youth have a positive outlook towards environmental issues which leads them to purchase eco friendly products.

\section{REFERENCES}

1. Achrol R.S. and Kotler P., (2012). Frontiers of the marketing paradigm in the third millennium,Journal of the Academy of marketing Science.40(1),35-52

2. Ahmad, S., Bangash, H., \& Ahmad Khan, S.(2009). Emotional Intelligence And Gender Differences. Sarhad J. Agric., 25 (1)

3. Farias S.A., Aruiar E.C. and Melo, F. V. S.,(2014). Store atmospherics and experiental marketing; A conceptual frame work and research propositions for an extraordinary customer experience. International Business research,7(2),897-99.

4. Fornell, C. and Bookstein, F. L. (1982). Two structural equation models: LISREL and PLS applied to consumer exit-voice theory. Journal of Marketing Research, 19(4), 440-453.

5. Hu, L., \& Bentler, P. M. (1999). Cutoff criteria for fit indexes in covariance structure analysis: Conventional criteria versus new alternatives. Structural Equation Modeling, 6, 1-55.

\section{Inference} influence the audio visual senses, touch/ feeling senses and of environmental issues regarding taste/ food senses. It is

6. Hulland, J, Chow, YH \& Lam, S 1996, 'Use of casual models in marketing research: A review', International Journal of Research in Marketing, 13, pp. 181-197

7. Krishna,A.,Lwin,M. O., \& Morrin, M.(2010). Product scent and memory. The Journal of Consumer Research,37(1),57-67.

8. Krishna,A.2012. An Integrative Review of Sensory Marketing;Engaging the senses to affect perception, Judgement and Behaviour. Journal of Consumer Psychology,22(1),332-351.

9. MacCallum, R.C., Browne, M.W., and Sugawara, H., M. (1996), "Power Analysis and Determination of Sample Size for Covariance Structure Modeling," Psychological Methods, 1 (2), 130-49.

10. Marsh, H. W., \&Hocevar, D., 1985, Application of confirmatory factor analysis to the study of self-concept: First- and higher-order factor models and their invariance across groups. Psychological Bulletin, 97, 562-582.

11. Nunnally, J. C., \&Berstein, I. H., 1994, 'Psychometric theory', 3rd edn, Mc-Graw-Hill, New York.

12. Yoon S.J. and Park J.E.,(2012). Do sensory and appeals influence brand attitude? Journal of Business Research,65(11), 1534-1542.

\section{AUTHORS PROFILE}

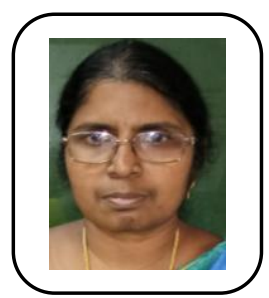

Dr. (Mrs). Hannah Frederick , M Com, M Phil $\mathrm{Ph} . \mathrm{D}$ is working as Associate Professor in Commerce, at the Deprtment of Commerce, Madras Christian College. Her has a total teaching experirence of 28 years. Her area of specialisation is Finance and Human resource management. She has produced one research scholar and is at presen guidng five research scholars towards Ph.D. She has also produced 7 M.Phil scholars. She has published 14 research articles in 3 National journals, 4 International journals, 6 UGC approved journals and 1 scopus Journal of which some were awarded the best paper. She is specialised in applying the latest statistical tools in research.She has chaired a session at a conference held by XIME, Bangalore. She has also delivered a lecture on Research Methodology at WCC. At present she is the member of the College Senatus and has held different positions at the college.

\section{Published By:}


Impact Of Environmental Issues On Consumer Senses Leading To Ecofriendly Buying Decisions

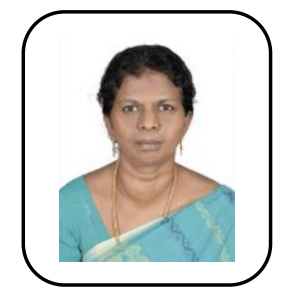

Mrs.J.Salomi Backia Jothi M.Com., M.Phil., NET

Is a part time Research Scholar (Commerce) at

Madras Christian College, Chennai. Affiliated to

University of Madras. She has published 3 research

articles in various national and international journals

and actively participating in various national

international conferences.. 